\title{
Lean Facility Management 4.0: A Case Study
}

\author{
Hanane RIFQI ${ }^{1}$, Souad BEN SOUDA ${ }^{2}$, Abdellah ZAMMA ${ }^{3}$, Sofia KASSAMI ${ }^{4}$ \\ Laboratory of Signals, Intelligence Artificial and Systems Distributed, (SSDIA) \\ ENSET Mohammedia, Hassan II University, Casablanca, Morocco \\ hanane.rifqi.14@gmail.com ${ }^{1}$, souadbensou@hotmail.com², ph_cnd@yahoo.fr ${ }^{3}$,sofiakassami@gmail.com ${ }^{4}$
}

\begin{abstract}
In the Industry 4.0 era, there is a multiplicity of concepts, tools and approaches that aim at operational excellence. Within these tools, Lean has proven its effectiveness through successful case studies around the world. The purpose of this article is to present a case study on the application of the Lean Management as a quality improvement methodology with Industry 4.0 technology solutions for a company in the field of Facilities Management (FM), an area that is lacking in publication. Lean 4.0 has enabled this organization to minimize waste in its processes and more specifically the maintenance process where the use of IoT, CMMS work mobility and various Lean tools have contributed to improve operational performance, social and economic performance.
\end{abstract}

Key words : Lean , Facility Management, Lean Facility, IoT, waste, GMAO, Maintenance, Lean Kaizen , Case study.

\section{INTRODUCTION}

The history of the industry began in the UK in the late 1980's. With increasing globalization, tight customer requirements, rapid technological development and competitive pressures, organizations are forced to adopt different concepts, practices and tools to improve their processes. The use of the latest technologies provide a competitive advantage [1], in order to secure and maintain this advantage, problem resolution must be fast and effective[2]with a strong commitment to improvement projects.

Lean as an approach is considered one of the business improvement tools that nowadays exist [3] ,it aims at eliminating waste and improving the speed of processes [4], its toolbox has different categories of tools including problem-solving tools, continuous improvement tools and flow management tools.Lean is not just a fancy term thrown around, but rather a whole philosophy [5]. A philosophy that focuses on the elimination of "waste" Mudas, all activities with no added value in the process, it also participates in increasing the speed of flows, it aims at reducing operational costs [6]these advantages lead to the overall efficiency improvement of organizations [7].
One of the challenges that a modern company faces is the effective implementation of Lean [8]. In this regard, there are several factors to be taken into consideration which leads to a successful Lean implementation and the main issues are [9] :

- Management support and commitment

- financial resources availability

- human resources management

- production process simplicity

- information technology

- competence for LM

- $\quad$ supportive culture and supply chain-wide integration

Through Lean and its implementation principles, many manufacturing industries around the world have proven its effectiveness in reducing their product costs, increasing their profits[10], the flexibility [11]In this context that Lean principles can be applied in FM processes to identify valueadded and non-value-added activities[12] and the application presented in this article will unveil all the benefits and advantages of Lean 4.0 with the various technology solutions in Industry 4.0 that have supported the lean application and filled the weakness of the Lean toolbox..

In this case study, the organization has exploited a very important number of Lean tools (5S, Standardized Work, Brainstorming, PDCA, Root cause analysis, Visual Controls, Kanban, ......) and is expanding towards solutions, new technologies and techniques of the industry 4.0 where the most important technologies are: the Internet of Things, RFID technology and CMMS.

For a better presentation, this document is organized into three supplementary sections in addition to this introduction. The next section is devoted to a review of the Lean paradigm and its application in facilities management in the 4.0 industry era. The third section includes all the actions taken to implement Lean Facility 4.0 in this company and the gains achieved after its implementation. A conclusion and some perspectives will be discussed in the fourth and last sections.

\section{LITERATURE REVIEW}

\subsection{Lean Concept}

The literature which covers LM is very vast[13]. The true origin of Lean Manufacturing LM is the Toyota Production System (TPS), pioneered by Japanese engineers TaiichiOhno 
and Shigeo Shingo and developed in the 1950s in Japan.[14]. However, the term "lean manufacturing" was proposed by Krafcik (1988), sometime after the TPS was first introduced, and transmitted to the industrial world by researchers at the Massachusetts Institute of Technology's International Motor Vehicle Program[15]. The LM can be described from many perspectives such as a philosophy, a process, a way of thinking, a set of principles, an approach, a set of tools and techniques, a concept, a system, a practice, a program, a manufacturing paradigm or a model [16]. At toyota, LM is seen as a philosophy that helps make the system effective and efficient for industries by eliminating waste caused by non-value added activities. These wastes are called by the Japanese"Mudas"[17], they are considered eight types and are generally: waiting, overproduction, rework, motion, transportation, processing, inventory, and intellect [18](see table 1). Despite the fact that the main and essential objective of Lean is to minimize these types of waste But achieving zero waste remains an unattainable goal[19].

\begin{tabular}{|c||c||c||c||}
\hline Transport & Inventory & Motion & Waiting \\
\hline \hline $\begin{array}{c}\text { Movement of product } \\
\text { between operations, and } \\
\text { locations. }\end{array}$ & $\begin{array}{c}\text { Work in progress (WIP) } \\
\text { and stocks of finished } \\
\text { goods and raw materials }\end{array}$ & $\begin{array}{c}\text { Physical movement of a } \\
\text { person or machine whilst } \\
\text { conducting an operation. }\end{array}$ & $\begin{array}{c}\text { Act of waiting for a } \\
\text { machine to finish, for } \\
\text { product to arrive, ...etc. }\end{array}$ \\
\hline Overproduction & Over-processing & Defects & Under utilization \\
\hline \hline $\begin{array}{c}\text { Over producing product } \\
\text { beyond what the } \\
\text { customer has ordered. }\end{array}$ & $\begin{array}{c}\text { Conducting operations } \\
\text { beyond those that customer } \\
\text { requires. }\end{array}$ & Product rejects and & rework within processes. \\
responsibiliting worker for tasks, \\
poor job tools available
\end{tabular}

Table 1: Different types of waste in LM [20]

In many industrial processes, non-value-added activities can exceed $90 \%$ of a plant's total activity[21]. However, Lean techniques are good alternatives that aim at optimizing existing resources before investing in new technologies[22]. The same goes for its methods and tools where they exceed 100 tools available for its implementation[3]such as Total Productive Maintenance (TPM), Total Quality Management (TQM), (FMEA), 5S, Single Minute Exchange of Die (SMED), Quality Function Deployment (QFD), Cellular Layout, Pull Production System, Visual Controls, Kaizen, Kanban, Poka Yoke, Value Stream Mapping (VSM), and more. These tools are classified in the TPS temple includes the essential elements in the lean concept for a stable and rigid structure (see figure 1). However, the choice and selection of these tools is independent [23].

\subsection{Lean Facilities Management}

With the publication of the two books Lean Thinking by Womack and Jones and The Machine that Changed the World by Womack, Jones and Roos, the familiarization of the term "lean" has become very popular in various sectors of activity other than production and manufacturing[24].As long as there is waste, lean can be used, which means that its application is not limited exclusively to manufacturing areas[25].
Lean thinking aims at continuous improvement through the reduction of : equipment, staff and human effort to achieve better results relative to the real needs of customers[26] which is similar to what facility management preaches, where its task is to help customers and consumers getting the most out of their properties and facilities, with an emphasis on reducing costs and non-added value[27] . Figure 2 presents a Venn diagram that links Lean and FM by showing the similarities and objectives that they share which are:

- Elimination of non-value added activities

- Reduction of Costs

- Elimination of inefficiency

- Customer orientation

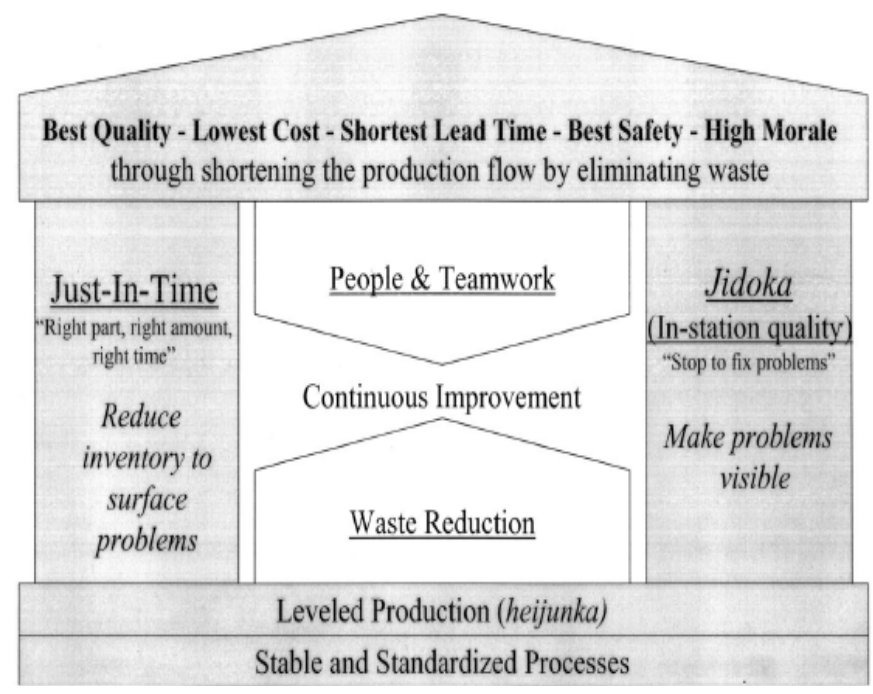

Figure 1: Toyota Production System TPS Temple[28]

There is also a necessary need to seek continuous improvements in service deliveries, due to increasing expectations and demand for quality FM services in general[29]. Value for FM organizations is essential in the collaboration with all their stakeholders in the workplace [30]and the core essence of FM is to continuously demonstrate value and optimize performance[31]. Therefore, Lean as a continuous improvement approach can improve the FM organizations processes by identifying the actual value creation process between input and output and providing tools to manage value creation[32].

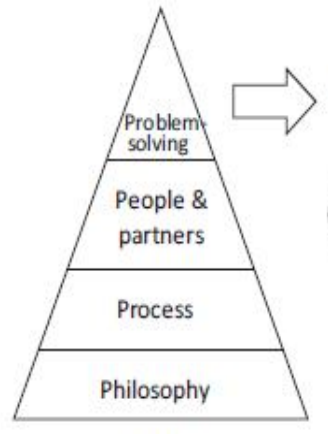

Lean

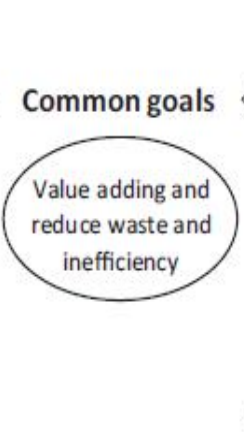

Customer-oriented

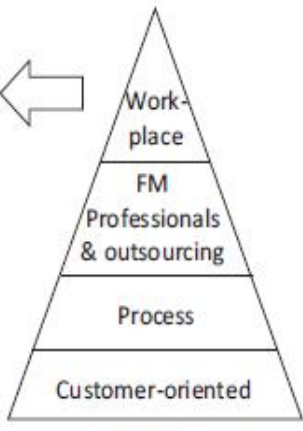

FM
Figure 1: Common goals between Lean and FM [27] 
The implementation of Lean in a non-manufacturing organization can be an overwhelming task[33]. Each organization has its own vision of Lean methodology, but the success of its implementation is closely linked to the work culture and ongoing efforts to create a value system approach [34] and to derive long-term benefits from the Lean concept, organizations must focus on building an appropriate culture, where that culture must represent the values, traditions and ways of thinking that build the identity of the organization [35].

\subsection{Lean Facility 4.0}

The fourth industrial revolution and the emergence of its technologies imposed it necessity for both lean and facility management concepts, in the aim to be adapted and take advantage of the Industry 4.0 tools and technologies. This industrial revolution can solicit lean and FM and force them to face the short tead time and customer requirements.

For Lean, Industry 4.0 offers new tools and techniques that can be solutions to its projects as it can participate in stabilizing and supporting the implementation of its principles [36]. It also allows more data to be collected in real time throughout the value chain and via the IoT different processes can be fed in real time by cognitive algorithms [37].

For FM, the industry 4.0 has participated in the improvement of maintenance towards a maintenance 4.0 [38] and all the technologies that connect human with machine. Industrial Thinking 4.0 and the Internet of Things (IoT) are revolutionizing operations through better visibility, connectivity and improved predictive maintenance (PdM) organization capabilities, resulting in improved reliability and service delivery [39].The integration of these three concepts Lean, FM and Industry 4.0 produces a facilities environment with maximum added value and supported by the latest technologies and tools.

\section{CASE STUDY}

\subsection{Company Background}

This article is a case study of a successful application of Lean Facility 4.0 to various maintenance processes and facility operations in a site of more than 50 hectares. The FM operations, multi-technical and multi-service maintenance of the buildings on this site are managed by a leading FM company based in North Africa which is the case company.

In general, FM companies are engaged through fixed term contracts with their customers, which may be renewable based on customer satisfaction, achievement of objectives and other factors. For this reason the company has considered implementing Lean 4.0 in this site to the aim to:

- Reduce the costs related to the various operations carried out by the company
- Improve the service qualitywith a higher response rate to customer requests.

- Improve customer satisfaction to ensure signature for any contract renewal

- Create a culture of continuous improvement in the different company processes

The company staff with a European consulting organization strives for operational excellence through the success of the different projects carried out in the company and the application of Lean has given fruitful and appreciable results by its main stakeholders.

\subsection{Lean Implementation}

The implementation of the Lean 4.0 concept has gone through two main phases. The first one is achieved in seven Months implementation in which the five principles of Lean were applied on the overall site and the second phase which is composed of several Lean-Kaizen projects in the aim of achieving perfection through continuous improvement.LeanKaizen" means the continuous elimination of NVA activities through the implementation of small changes within the organization[40]. It aims at continuous improvement as a way to achieve Lean objectives [41]. Kaizen is a separate philosophy that can be used as a continuous improvement method within Lean [42] and at Toyota it is seen as a kind of corporate culture that supports continuous organizational learning [41].

\subsubsection{Lean principles application}

To apply Lean, the company has followed the five principles recognized for its implementation.

\section{Principe 1: Define value}

Holding meetings with the customers, company managers and the foremen in order to understand customer expectations and the services to be improved.

\section{Principe 2 : Identify value stream}

Visualization of the current state is carried out to decompose and analyze the different steps in the processes, the procedures followed in the execution of the client's service. The objective was to detect and identify non-value added activities that can improve the flow of value.

\section{Principe 3 : Create Flow}

Continuous flow creation without wastes(detected wastes). The value flow can be related to the cycle time of the work order process or of the services provided. The value flow in FM is the cycle time allowed for each service provided (process cycle of interventions and operations).

\section{Principe 4 : Establish Pull}

In FM there are several services that can be delivered without a customer request, such as technical rounds and preventive maintenance that are carried out according to a 
schedule. On the other hand, all intervention requests are processed and provided unless the customer requests it (request for accompaniment, repair,...) (see Figure 3).

\section{Principe 5 : Pursuit of Perfection}

As all organizations, the company aims for perfection and excellence in its deliveries, for this reason it has engaged in mini Lean-Kaizen projects either by an implicit or explicit need expressed by the customer.

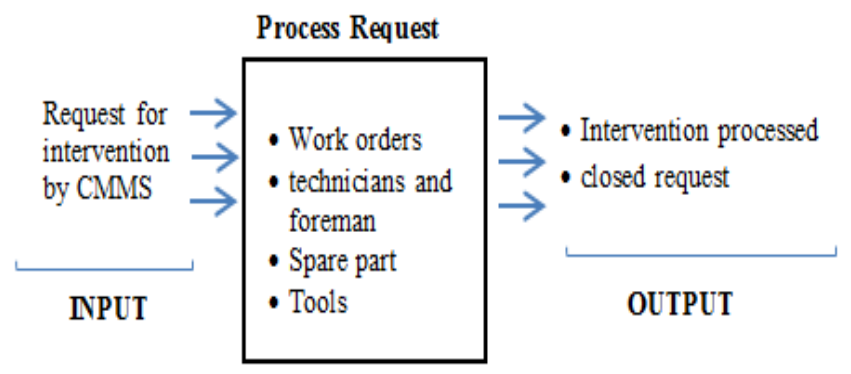

Figure 3: Pull flow of the process request

\subsubsection{Wastes and no value activities discovered}

By applying Lean Facility 4.0 to the different business activities carried out by the company and which are:

- Cleaning and sanitation of the facilities,

- Maintenance of green spaces and waste management

- Building maintenance

- Hygiene, prevention, safety and security.

The majority of projects were devoted to maintenance due to their importance and criticality in FM. This section unveils some of the issues, actions and solutions of this Lean Facility 4.0 project, which are classified according to the waste categories

\section{Over maintenance:}

The maintenance task list are not revised for years and as long as the equipment is in the Ageing phase, the maintenance ranges have to be modified in a more optimized way. There are operations and instructions without added value in the maintenance task list, for example the elimination of the cleaning of filters by changing them directly. These actions are based on the optimization of the preventive maintenance task listbased on the reliability of the equipment and the experience feedback.

\section{Inventory:}

The organization's inventory meets a monitoring problem and its visualization in real time, the inventory control is carried out weekly or sometimes monthly risk to cause stock rupture either for PDR (spare parts) or for consumables. This problem generates a lot of waste and expectations which are due to the long duration of ordering for several items.
Currently, the stock management and procurement (Inventory security threshold) is carried out via CMMS, which guarantees $100 \%$ availability of parts since it ensures the launch of the safety stock and a high control of parts availability. Figure 4 is a screenshot of the inventory management from the CMMS which allows a general visualization of inventories and procurement.

\section{Extra processing steps:}

The previous CMMS version was of the heavy CMMS type, where the request for intervention operation takes a long time and generates internal problems ( waiting and long cycle) and external problems (customer complaints about the delay in intervention completion).

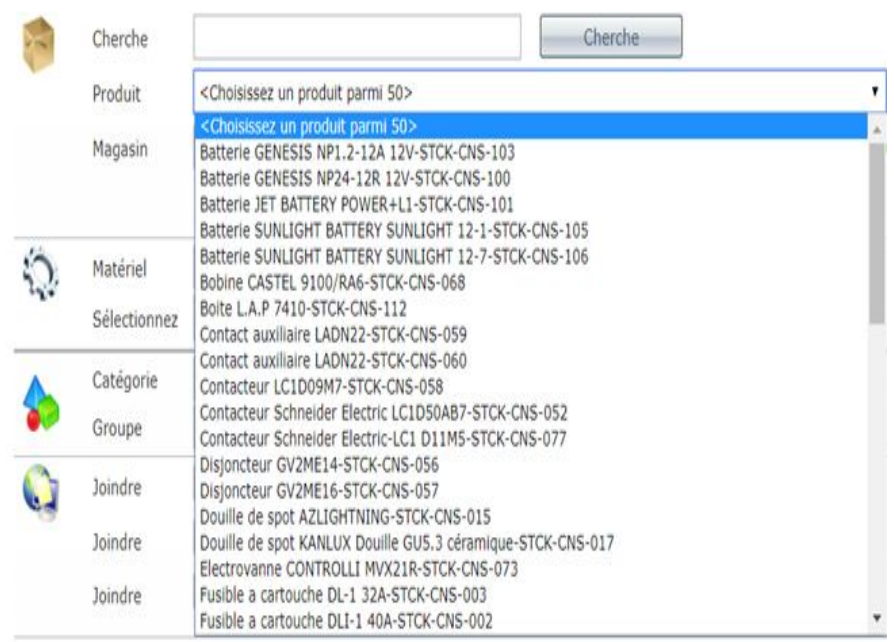

Figure 3: Platform for inventory management in CMMS

The procedure begins with a methods officer who must print the work orders and requests for interventions for the interveners. After the interventions, the paper reports are typed and recorded on the system via the methods officer.

Now, with the transition to the CMMS MOBILITY WORK, intervention requests are sent directly to the technicians' cell phones, adding that the reports are also written and transmitted by their Smartphones. Figure 5 is a screenshot of the CMMS MOBILITY WORK from a smartphone of one of the technicians, which allows him to consult the interventions to be carried out, write reports, create an intervention request and several useful actions for the smooth running of the maintenance services.

\section{Motion:}

The site exceeds 50 hectares, it contains a very important number of buildings of more than 5 floors. Teams must perform daily rounds and corrective actions in these buildings by walking in the site. This action generate a lot of wasted time and physical energy, while the realization of timing and diagrams like spaghetti led the pilot team to dispose of electric motorcycles for the corrective interventions. This solution reduced repair time and liberated time for other tasks and interventions. 
Another point related to the complexity of the roads and the important number of buildings which participate in the realization of the daily rounds in 2 hours instead of one hour for each technician of the team. The use of IoT as a solution allowed the elimination of technical rounds for some equipment, adding real-time supervision and control which was not available before, adding the ease to detect failures and problems. Figure 6 shows a schematic of the current functioning of the IoT in the company with the assistance of a LoRaWan network.

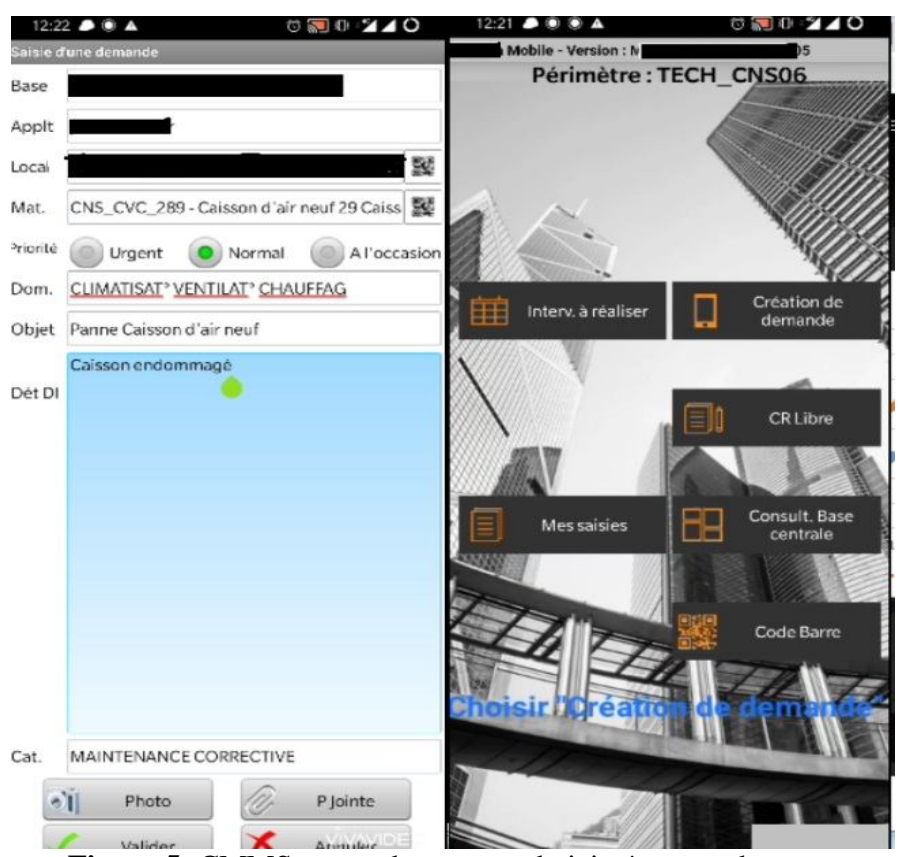

Figure 5: CMMS screenshot on a technician's smartphone

\section{Defects:}

In the interventions history, the root causes of the failures are not identified so that there is a redundancy of several interventions for the same problem. In order to eliminate these failures in a definitive way, the realization of a FMEA analysis was an adequate solution that allowed the elimination of the defects at the root source.

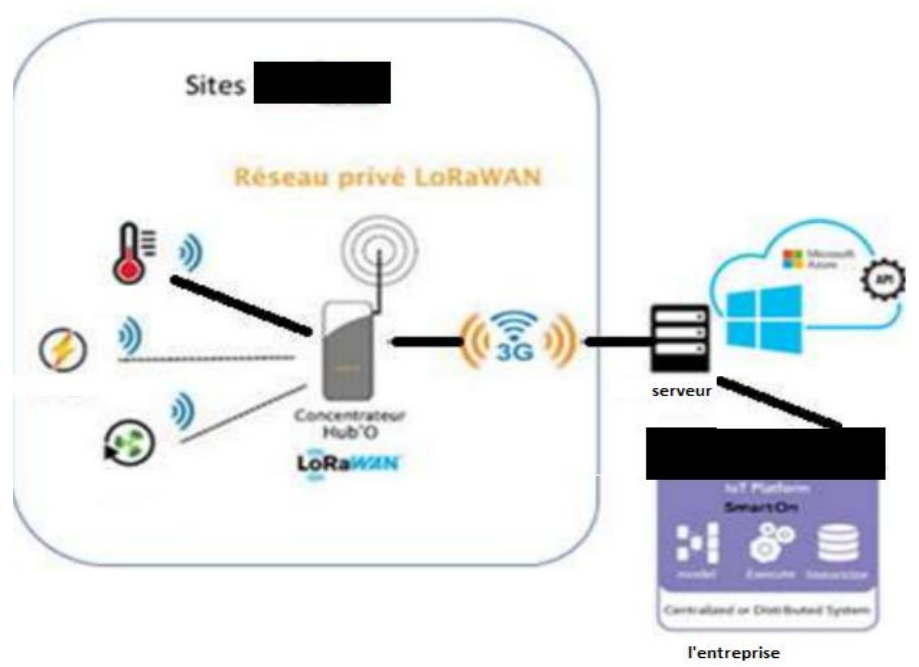

Figure 6: Functioning of the IoT in the site

\section{Transportation:}

The store is located at the extremity of the site which generates a very important time of repair and the same for the machine data sheets which requires mobility. A study is carried out using the $\mathrm{ABC}$ diagram to calculate the inventory of the first emergency response is installed in the service car. currently via the CMMS, the documentation access is available by direct access from the smart phones of the team members.

\subsection{Results \& Discussion}

Table 2 presents the different gains obtained through the projects presented in the previous section. Maintenance presents $80 \%$ of the Lean 4.0 project since it's the FM essence. These achievements have also minimized the rate of customer complaints against delays in the processing of intervention requests since the penalties are set at 50 USD for each 24 hours of tardiness after the declaration of the intervention request, adding that these actions have allowed the company to renew the contract for 2 more years.

Organizational culture and change acceptance can have a great impact on the lean implementation success [43]. The social factor played an important role in the success of this application. In this company, the staff was highly motivated during the various stages of the Lean Facility 4.0 continuous improvement projects, especially since the company offers many benefits and salary increases to its employees. The staff also believes in the need for continuous improvement, especially since the loss of the market will lead to the loss of their positions and, on the other hand, the implementation will allow them to perform their usual tasks easily and with less effort.

\begin{tabular}{|l|l|}
\hline types of waste & Gain obtained \\
\hline Inventory & Parts availability at 100\%. \\
\hline $\begin{array}{l}\text { Over } \\
\text { maintenance }\end{array}$ & $\begin{array}{l}\text { Minimization of the time allocated to the } \\
\text { ranges } \\
\text { Perfection in the performed tasks }\end{array}$ \\
\hline Motion & $\begin{array}{l}\text { Round time reduced to } 85 \% \\
\text { Technical intervention time reduced to } \\
50\end{array}$ \\
\hline $\begin{array}{l}\text { Extra } \\
\text { processing } \\
\text { steps }\end{array}$ & $\begin{array}{l}\text { Intervention time optimization } \\
\text { Immediate saving of all reports } \\
\text { Paper and ink toners consumption } \\
\text { minimization to the } \\
\text { instructions and work orders printing. }\end{array}$ \\
\hline Defects & Elimination of reproducible failures \\
\hline Transportation & Repair time reduction \\
\hline
\end{tabular}

Table 2: gain obtained by type of waste 
At the same time the social aspect during this implementation was enhanced with improvements such as:

- Morale and commitment of the employees, especially through the lean-kaizen projects in which their manager takes into consideration their proposals and improvement suggestions (during brainstorming meetings).

- Working conditions by minimizing the tasks difficulty and the efforts applied during the execution.

- Team spirit and cohesion among all its members

Finally, the pilot team has set monitoring indicators for this application that will be included in the operational dashboard with the other performance indicators and also on the management review of this year 2020. These performance indicators include an indicator on the completion rate of the lean-Kaizen projects, another indicator on the percentage of elimination of non-value added activities and the progress of customer complaints related to intervention request.

\section{CONCLUSION}

FM companies, like all forms of business, are looking to improve and follow the technological evolution in the era of Industry 4.0. the practice of FM embraces all aspects of asset management, with the primary goal of improving the life quality of owner/users ( customers ) in an efficient and costeffective way [31].

Building facility managers are expected to maximize the level of performance while maintaining a limited maintenance budget [44]where lean can contribute to minimize costs by reducing non-value added activities. Adding that FM and Lean meet in the value maximization and customer satisfaction, for this reason the company decided to implement Lean 4.0 with the objective of:

- Maximizing value

- Improve the working conditions of all technicians and team leaders

- Satisfying customers

- Following the 4 th industrial revolution

This document illustrates an application of the Lean 4.0 Concept in a specialized FM company in which the company reduced several non-value-added activities and improved the quality of its deliveries.

This implementation was divided into two main phases. The first is dedicated to the implementation of the five principles of Lean within a period of 7 months for the entire site and the second phase is the generation of Lean-Kaizen projects in the objective of perfection seeking through continuous improvement and the conversion of problems encountered into opportunities. This application of Lean Facility 4.0 has enabled:
- Availability of spare parts at $100 \%$

- Minimization of the time allocated to preventive ranges

- Perfection in the tasks performed

- Reduction of the time of rounds to $85 \%$ and technical interventions to $50 \%$ with the time of repair

- Optimization of intervention time

- Immediate records of all daily reports (corrective and preventive)

- Minimization of paper and ink toners consumption allocated to printing instructions and work orders

- The elimination of repeatable defects

- Minimizing the claims number against delays in processing interventions requests

For the company's perspectives, it will start a major BIM integration project, with the possibility of its alignment with Lean. In particular, BIM can provide information on assets required by FM managers from a full life-cycle perspective [45], which will minimize several types of waste , furthermore Lean will facilitate and optimize the time and cost of BIM integration for the enterprise.

The company is also aiming at another lean kaizen project to enable the integration of the IoT with the CMMS to allow the technicians and their team leaders to control it from their Smartphones and the intervention will be immediate without intermediaries (the IoT data is currently sent to a supervision room).

For research prospects, we plan to implement a Lean Institute application to identify the various wastes that a university can experience and how to minimize them.

Finally, the objective of all Lean tools is to eliminate Mudas in the most efficient way possible to offer consumers the best value, but in reality Lean as a concept can just significantly reduce waste, but not eliminate it, and the benefits obtained from its application have not always lived up to the expectations of adoptive organizations [46].That's can be explained by the complexity of processes [47], which leads to new principles as well as the agility to face constantly changing market demand [48].

\section{REFERENCES}

[1] "Applying Smart Contract in E-logistics for Monitoring and Control," IJETER, vol. 8, no. 2, pp. 247-250, Feb. 2020, doi: 10.30534/ijeter/2020/01822020.

[2] F. Gaspar and F. Leal, "A methodology for applying the shop floor management method for sustaining lean manufacturing tools and philosophies: a study of an automotive company in Brazil," IJLSS, vol. ahead-ofprint, no. ahead-of-print, Jun. 2020, doi: 10.1108/IJLSS-09-2019-0098.

[3] I. Leksic, N. Stefanic, and I. Veza, "The impact of using different lean manufacturing tools on waste reduction," Adv produc engineer manag, vol. 15, no. 
1, pp. $\quad$ 81-92, Mar. 2020, doi: 10.14743/apem2020.1.351.

[4] F. A. A B, "Lean Six Sigma Implementation on Reducing Incoming Processes Time in QA Department at Reckitt Benckiser Sdn Bhd," IJATCSE, vol. 9, no. 1.1 S I, pp. 252-258, Feb. 2020, doi: 10.30534/ijatcse/2020/4591.12020.

[5] S. Zaheer, M. S. Amjad, M. Z. Rafique, and M. A. Khan, "A K-Chart based implementation framework to attain lean \& agile manufacturing," Int. J. Prod. Manag. Eng., vol. 8, no. 2, p. 123, Jul. 2020, doi: 10.4995/ijpme.2020.12935.

[6] J. Antony et al., "An exploratory study into the use of Lean Six Sigma to reduce medication errors in the Norwegian public healthcare context," LHS, vol. 32, no. 4, pp. 509-524, Sep. 2019, doi: 10.1108/LHS-122018-0065.

[7] S. A. Albliwi, J. Antony, and S. A. halim Lim, "A systematic review of Lean Six Sigma for the manufacturing industry," Business Process Mgmt Journal, vol. 21, no. 3, pp. 665-691, Jun. 2015, doi: 10.1108/BPMJ-03-2014-0019.

[8] R. El-Khalil, "Lean manufacturing alignment with respect to performance metrics multinational corporations case study," IJLSS, vol. ahead-of-print, no. ahead-of-print, Apr. 2020, doi: 10.1108/IJLSS-102017-0118.

[9] M. Ghobakhloo, M. Fathi, D. B. M. M. Fontes, and N. Tan Ching, "Modeling lean manufacturing success," Jnl of Modelling in Management, vol. 13, no. 4, pp. 908-931, Nov. 2018, doi: 10.1108/JM2-03-2017-0025.

[10] N. Vamsi Krishna Jasti and A. Sharma, "Lean manufacturing implementation using value stream mapping as a tool: A case study from auto components industry," Lean Six Sigma Journal, vol. 5, no. 1, pp. 89-116, Feb. 2014, doi: 10.1108/IJLSS-04-2012-0002.

[11] M. B. A.M, "Green and Lean Industrial Engineering Practices in Selected Manufacturing Units in Andhra Pradesh: Statistical Analysis," IJETER, vol. 8, no. 5, pp. 1768-1775, May 2020, doi: 10.30534/ijeter/2020/45852020.

[12] V. Sharma, J. Abel, M. Al-Hussein, K. Lennerts, and U. Pfründer, "Simulation application for resource allocation in facility management processes in hospitals," Facilities, vol. 25, no. 13/14, pp. 493-506, Oct. 2007, doi: 10.1108/02632770710822599.

[13] O. P. Yadav, B. P. Nepal, M. M. Rahaman, and V. Lal, "Lean Implementation and Organizational Transformation: A Literature Review," Engineering Management Journal, vol. 29, no. 1, pp. 2-16, Jan. 2017, doi: 10.1080/10429247.2016.1263914.

[14] J. C. Hernandez-Matias, J. R. Ocampo, A. Hidalgo, and A. Vizan, "Lean manufacturing and operational performance: Interrelationships between humanrelated lean practices," JMTM, vol. 31, no. 2, pp. 217235, Sep. 2019, doi: 10.1108/JMTM-04-2019-0140.

[15] J. Womack, D. T. Jones, and D. Roos, "The machine that changed the world : the story of lean production -Toyota's secret weapon in the global car wars that is revolutionizing world industry," undefined, 1991.
/paper/The-machine-that-changed-the-world-\%3A-thestory-of-Womack-

Jones/4cac51c7ab0b49824feab0b5645b22eb22b378e5 (accessed Aug. 26, 2020).

[16] A. Vanichchinchai, "Exploring organizational contexts on lean manufacturing and supply chain relationship," JMTM, vol. 31, no. 2, pp. 236-259, Aug. 2019, doi: 10.1108/JMTM-01-2019-0017.

[17] J. Muraliraj, S. Zailani, S. Kuppusamy, and C. Santha, "Annotated methodological review of Lean Six Sigma," Lean Six Sigma Journal, vol. 9, no. 1, pp. 249, Mar. 2018, doi: 10.1108/IJLSS-04-2017-0028.

[18] W. T. Shirey, K. T. Sullivan, B. Lines, and J. Smithwick, "Application of Lean Six Sigma to Improve Service in Healthcare Facilities Management: A Case Study," Journal of Facility Management Education and Research, vol. 1, no. 1, pp. 9-18, Jan. 2017, doi: 10.22361/jfmer/78724.

[19] "A Comparative Analysis of Industrial Leanness Index, Weak Areas, Ranking Score and Performance Importance Score for Indian Food Processing Industries," IJETER, vol. 8, no. 5, pp. 2036-2046, May 2020, doi: 10.30534/ijeter/2020/93852020.

[20] I. Q. Abdulhussein, "INTEGRATION OF ERGONOMIC ASPECTS AND LEAN SIX SIGMA METHODOLOGIES INTO INDUSTRIAL WORKSTATIONS," p. 285.

[21] P. Dhiravidamani, A. S. Ramkumar, S. G. Ponnambalam, and N. Subramanian, "Implementation of lean manufacturing and lean audit system in an auto parts manufacturing industry - an industrial case study," International Journal of Computer Integrated Manufacturing, vol. 31, no. 6, pp. 579-594, Jun. 2018, doi: 10.1080/0951192X.2017.1356473.

[22] C. C. Fernandes Junior and L. T. Pinto, "Productivity increase in a large size slaughterhouse: a simulation approach applying lean manufacturing," IJLSS, vol. ahead-of-print, no. ahead-of-print, Jun. 2020, doi: 10.1108/IJLSS-02-2018-0012.

[23] B. G. Rüttimann and M. T. Stöckli, "Going beyond Triviality: The Toyota Production System-Lean Manufacturing beyond Muda and Kaizen," JSSM, vol. 09, no. 02, pp. 140-149, 2016, doi: 10.4236/jssm.2016.92018.

[24] M. Jahan and A. Doggett, "A Study on the Students' Perceptions of the Applicability of Lean Principles at Universities," in 2015 ASEE Annual Conference and Exposition Proceedings, Seattle, Washington, Jun. 2015, p. 26.115.1-26.115.17, doi: 10.18260/p.23456.

[25] C. E. Pérez-Pucheta, E. Olivares-Benitez, H. MinorPopocatl, P. F. Pacheco-García, and M. F. PérezPucheta, "Implementation of Lean Manufacturing to Reduce the Delivery Time of a Replacement Part to Dealers: A Case Study," Applied Sciences, vol. 9, no. 18, p. 3932, Sep. 2019, doi: 10.3390/app9183932.

[26] D. L. de M. Nascimento, O. L. G. Quelhas, M. J. Meiriño, R. G. G. Caiado, S. D. J. Barbosa, and P. Ivson, "FACILITY MANAGEMENT USING DIGITAL OBEYA ROOM BY INTEGRATING BIM-LEAN APPROACHES - AN EMPIRICAL 
STUDY," JOURNAL OF CIVIL ENGINEERING AND MANAGEMENT, vol. 24, no. 8, pp. 581-591, Dec. 2018, doi: 10.3846/jcem.2018.5609.

[27] S. Gao, L. Sui Pheng, and W. Tay, "Lean facilities management: preliminary findings from Singapore's international schools," $F$, vol. 38, no. 7/8, pp. 539558, Mar. 2020, doi: 10.1108/F-07-2019-0076.

[28] J. K. Liker and J. M. Morgan, "The Toyota Way in Services: The Case of Lean Product Development," $A M P$, vol. 20, no. 2, pp. 5-20, May 2006, doi: 10.5465/amp.2006.20591002.

[29] S. Gao, L. Sui Pheng, and W. Tay, "Lean facilities management: preliminary findings from Singapore's international schools," $F$, vol. 38, no. 7/8, pp. 539558, Mar. 2020, doi: 10.1108/F-07-2019-0076.

[30] K. Alexander, "Co-creation of value in FM," 2012, doi: 10.13140/2.1.3348.8001.

[31] S. Terreno, S. Asadi, and C. Anumba, "An Exploration of Synergies between Lean Concepts and BIM in FM: A Review and Directions for Future Research," Buildings, vol. 9, no. 6, p. 147, Jun. 2019, doi: 10.3390/buildings9060147.

[32] T. Jylhä and S. Junnila, "Learning from lean management - going beyond input-output thinking," Facilities, vol. 31, no. 11/12, pp. 454-467, Aug. 2013, doi: 10.1108/F-11-2011-0097.

[33] A. L. Schultz, "INTEGRATING LEAN VISUAL MANAGEMENT IN FACILITIES MANAGEMENT SYSTEMS," p. 303.

[34] A. Taylor, M. Taylor, and A. McSweeney, "Towards greater understanding of success and survival of lean systems," International Journal of Production Research, vol. 51, no. 22, pp. 6607-6630, Nov. 2013, doi: 10.1080/00207543.2013.825382.

[35] T. Conti, "The dynamics of value generation and their dependence on an organisation's internal and external value system," Total Quality Management \& Business Excellence, vol. 21, no. 9, pp. 885-901, Sep. 2010, doi: 10.1080/14783363.2010.487701.

[36] T. Wagner, C. Herrmann, and S. Thiede, "Industry 4.0 Impacts on Lean Production Systems," Procedia CIRP, vol. 63, pp. 125-131, 2017, doi: 10.1016/j.procir.2017.02.041.

[37] G. Arcidiacono and A. Pieroni, "The Revolution Lean Six Sigma 4.0," International Journal on Advanced Science, Engineering and Information Technology, vol. 8, no. 1, p. 141, Feb. 2018, doi: 10.18517/ijaseit.8.1.4593.

[38] P. Poor, J. Basl, and D. Zenisek, "Predictive Maintenance 4.0 as next evolution step in industrial maintenance development," in 2019 International Research Conference on Smart Computing and Systems Engineering (SCSE), Colombo, Sri Lanka, Mar. 2019, pp. 245-253, doi: 10.23919/SCSE.2019.8842659.

[39] F. Koenig, P. A. Found, and M. Kumar, "Innovative airport 4.0 condition-based maintenance system for baggage handling DCV systems," Int J Productivity \& Perf Mgmt, vol. 68, no. 3, pp. 561-577, Mar. 2019, doi: 10.1108/IJPPM-04-2018-0136.
[40] A. K. Dhingra, S. Kumar, and B. Singh, "Cost reduction and quality improvement through LeanKaizen concept using value stream map in Indian manufacturing firms," Int J Syst Assur Eng Manag, vol. 10, no. 4, pp. 792-800, Aug. 2019, doi: 10.1007/s13198-019-00810-z.

[41] C. O. Chan and H. L. Tay, "Combining lean tools application in kaizen: a field study on the printing industry," Int J Productivity \& Perf Mgmt, vol. 67, no. 1, pp. 45-65, Jan. 2018, doi: 10.1108/IJPPM-09-20160197.

[42] J. Singh and H. Singh, "Continuous improvement approach: state-of-art review and future implications," Lean Six Sigma Journal, vol. 3, no. 2, pp. 88-111, Jun. 2012, doi: 10.1108/20401461211243694.

[43] M. Alefari, M. Almanei, and K. Salonitis, "Lean manufacturing, leadership and employees: the case of UAE SME manufacturing companies," Production \& Manufacturing Research, vol. 8, no. 1, pp. 222-243, Jan. 2020, doi: 10.1080/21693277.2020.1781704.

[44] D. Amos, Z. N. Musa, and C. P. Au-Yong, "A review of facilities management performance measurement," $P M$, vol. 37, no. 4, pp. 490-511, Aug. 2019, doi: 10.1108/PM-08-2018-0051.

[45] J. Patacas, N. Dawood, V. Vukovic, and M. Kassem, "BIM FOR FACILITIES MANAGEMENT: EVALUATING BIM STANDARDS IN ASSET REGISTER CREATION AND SERVICE LIFE PLANNING," p. 19.

[46] A. Ghobadian, I. Talavera, A. Bhattacharya, V. Kumar, J. A. Garza-Reyes, and N. O'Regan, "Examining legitimatisation of additive manufacturing in the interplay between innovation, lean manufacturing and sustainability," International Journal of Production Economics, vol. 219, pp. 457468, Jan. 2020, doi: 10.1016/j.ijpe.2018.06.001.

[47] M. HANSALI and A. GOURCH, "Précis théorique et épistémologique en supply chain management: Analyse de la crise de théorisation," Revue Française d'Economie et de Gestion, vol. 1, no. 2, 2020.

[48] M. HANSALI and A. GOURCH, "The role of collaboration in the supply chain of the automotive industry in Morocco," Revue Française d'Economie et de Gestion, vol. 1, no. 2, 2020. 